\title{
Subcutaneous neuroglial choristoma: an immunohistopathological case study
}

\author{
Selwa A F Al-Hazzaa, Charles S Specht, Ian W McLean, Laurence A Somers
}

Department of

Ophthalmic Pathology,

Armed Forces Institute of Pathology,

Washington DC, USA

C S Specht*

I W McLean

Pediatric Surgical Valley, PA, USA

L A Somers

${ }^{\star}$ Dr Specht is now at the Department of Pathology, Shadyside Hospital, Pittsburg, PA, USA.

Correspondence to:

Col I W McLean, Department

Armed Forces Institute of 20306-6000, USA.

Accepted for publication 29 June 1993
S A F Al-Hazzaa Associates, Huntingdon

of Ophthalmic Pathology Pathology, Washington DC,

Congenital nests of neuroepithelial tissue, probably representing either sequestered encephalocele or aberrant neuroectodermal migration in utero, may give rise to heterotopic neuroglial tissue masses.' The 'nasal glioma' is best known, although small subcutaneous heterotopic neuroglial masses may occur near the midline on the head and face, ${ }^{12}$ or in other locations, such as the chest wall. ${ }^{3}$ Periocular heterotopic neuroglial tissue has been documented in the orbit, ${ }^{456}$ in a lower eyelid, ${ }^{7}$ and with limbal dermoid. ${ }^{89}$ There may be associated central nervous system malformations. ${ }^{7}$ Neuroglial choristomas are heterotopic neuroglial masses with no clinical,

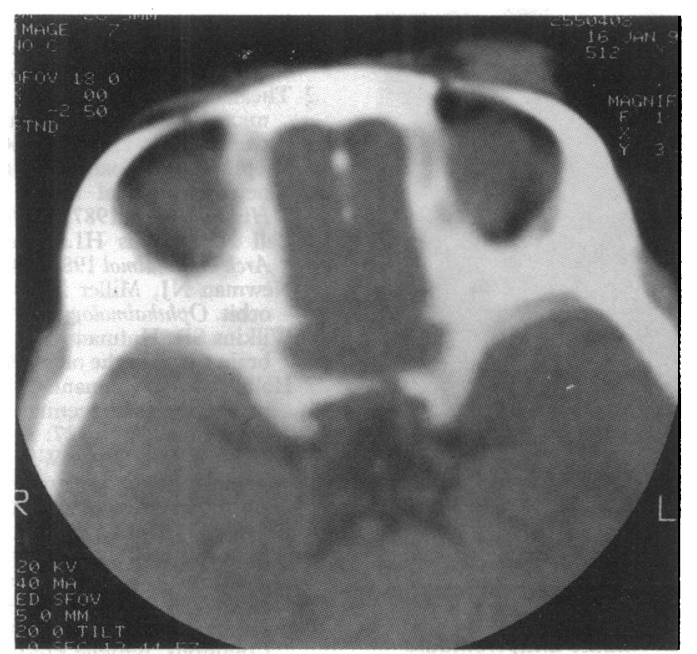

Figure 1 Unenhanced computed tomographic (CT) scan after the first surgical procedure, showing subcutaneous lesion over left superior orbital rim. Note that the underlying bone is intact.

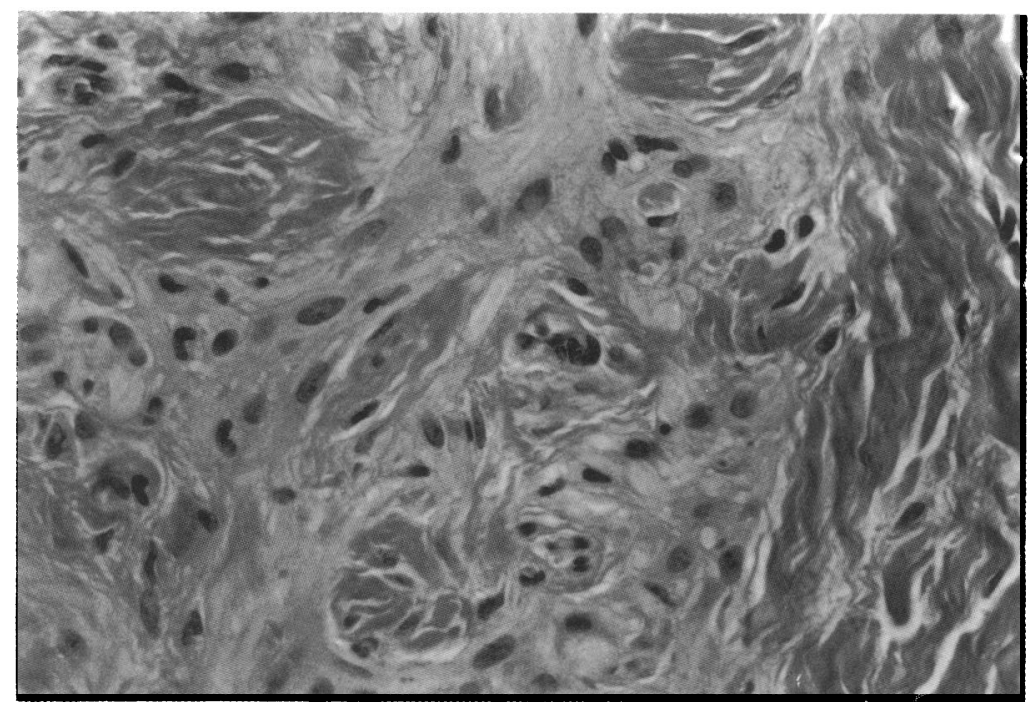

Figure 2 Benign glial cells with round to ellipsoidal nuclei and fibrillated cytoplasm infiltrate the fibrous subcutaneous connective tissue in this field. (Haematoxylin and eosin, magnification $\times 70$.) radiological, or histopathological evidence for origin from sequestered encephalocele.

\section{Case report}

A 3-month-old male infant had had a subcutaneous mass at the temporal end of the left eyebrow since birth. This measured $1.5 \mathrm{~cm}$ on examination. Dermoid cyst was diagnosed, and excision was attempted. At surgery, the lesion was more fleshy than a typical dermoid cyst. A subtotal excision was performed. Postoperative computed tomography showed no connection to the intracranial contents (Fig 1). The eyes, optic nerves, and brain were normal.

Seven weeks later the remaining lesion was excised. By then the residual supraorbital mass had grown, and a similar lesion was seen near the centre of the patient's forehead. This second lesion measured $1.5 \mathrm{~cm}$; it was not contiguous with the first. Gross total excision of both lesions was achieved at the second surgery. Wide excision was not performed because of the possible reconstructive surgery that such a procedure might necessitate.

The three surgical specimens were formalin fixed and paraffin embedded. Sections were studied with haematoxylin and eosin stain and the peroxidase antiperoxidase method for $\mathbf{S 1 0 0}$ protein and glial fibrillary acidic protein (GFAP).$^{10}$ The immunohistochemical chromogen was diaminobenzidine, which produces a dark brown stain.

All specimens showed glial cell infiltration of subcutaneous fibrous tissue and skeletal muscle (Fig 2). The intermingled glial cell processes resembled neuropil. These cells had round to ellipsoid nuclei with finely divided chromatin, occasional small nucleoli and smooth nuclear membranes. The pale eosinophilic cytoplasm was finely fibrillated. The glial cytoplasm and nuclei were $S 100$ protein positive (Fig $3 \mathrm{~A}$ ), and cytoplasmic filaments were GFAP positive (Fig 3B). There were no meningothelial cells, ependymal cells, or teratomatous elements; a very rare cell suggestive of a neuron was seen.

There was no further treatment. After 3 months, both lesions recurred locally. They grew to about the same size as before, and then remained stable over a 2 year follow up period. The child has been otherwise healthy and normal.

\section{Comment}

Subcutaneous heterotopic neuroglial tissue occurs most often in male children younger than 2 years of age, presenting as a painless, static, or slowly growing lesion. ${ }^{1}$ Dermoid cyst is a frequent preoperative diagnosis. The differential 


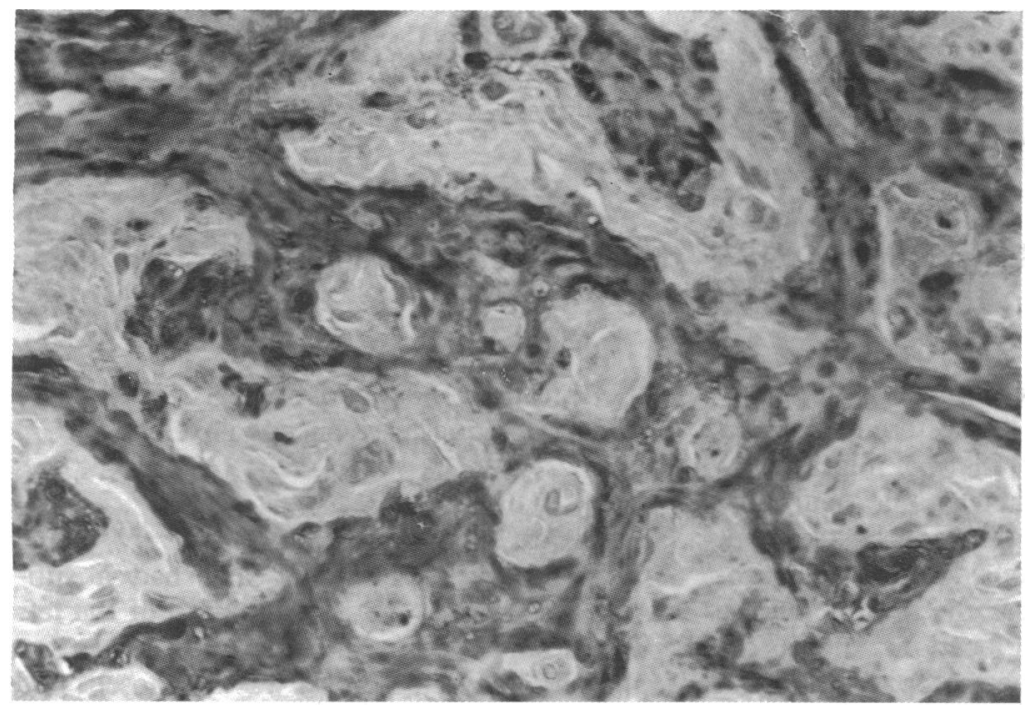

Fig $3 A$

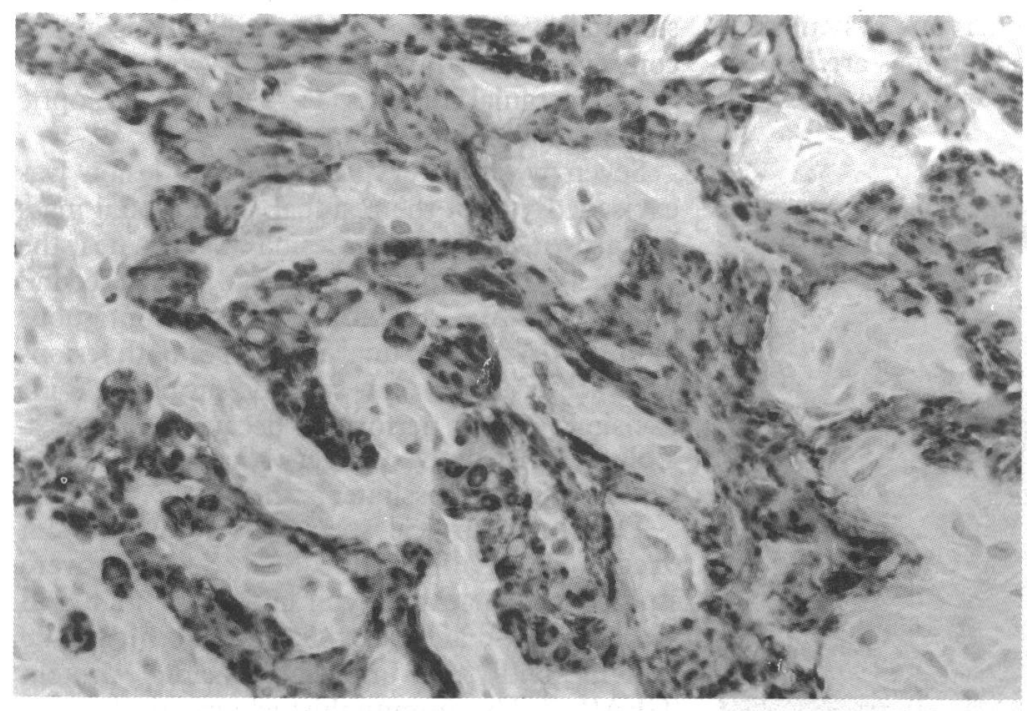

Fig $3 B$

Figure 3 In these fields the glial tissue is highlighted by nuclear and cytoplasmic staining for (A) S100 protein (peroxidase antiperoxidase with diaminobenzidene, magnification $\times 70$ ), and by staining of the glial cytoplasmic filaments for $(B)$ GFAP (peroxidase antiperoxidase with diaminobenzidine, magnification $\times 70)$. The positively stained areas are dark brown.

diagnosis includes haemangioma, fibroma or fibromatosis, and lipoma.

All forms of heterotopic neuroglial tissue are histologically similar, and contain mostly glial tissue, although neurons, ependymal cells, or meningothelial cells are occasionally seen. ${ }^{12}$ The neuroglial tissue tends to be locally infiltrative.
Old lesions in adults may be fibrotic. ${ }^{12}$ Several previous articles describe positive immunohistochemistry for S100 protein or GFAP in heterotopic neuroglial tissue. ${ }^{2371112}$ These methods provide sharp contrast between neuroglial tissue and connective tissue (Figs 3A, B), and are useful in fibrotic cases. ${ }^{2}$

Complete excision is the suggested treatment for neuroglial choristoma. Differentiating heterotopic neuroglial tissue (choristoma or sequestered encephalocele) from encephalocele with intracranial communication solely on histopathological or immunohistochemical grounds may be impossible, so clinical and radiological evaluation is important. ${ }^{11314}$ Coordination with a neurosurgical consultant is often necessary when a communicating encephalocele is suspected. When biopsy reveals a benign subcutaneous neuroglial lesion, with clinical and radiological features of neuroglial choristoma, our experience suggests that close clinical follow up alone may also be a reasonable approach.

The opinions and assertions contained herein are the private views of the authors and should not be construed as being official or as representing the views of the Department of the Army or the Department of Defense.

1 Yeoh GPS, Bale PM, de Silva M. Nasal cerebral heterotopia: the so-called nasal glioma or sequestered encephalocele and the so-called nasal glioma or sequestered en

2 Theaker JM, Fletcher CD. Heterotopic glial nodules: a light microscopic and immunohistochemical study. Histo pathology 1991; 18: 255-60.

3 Shepherd NA, Coates PJ, Brown AA. Soft tissue gliomatosis heterotopic glial tissue in the subcutis: a case report. Histopathology 1987; 11: 655-60.

4 Call NB, Baylis HI. Cerebellar heterotopia in the orbit. Arch Ophthalmol 1980; 98: 717-9.

5 Newman NJ, Miller NR, Green WR. Ectopic brain in the orbit. Ophthalmology 1986; 93: 268-72.

6 Wilkins SR, Hofmann RJ, Byrd WA, Font RL. Heterotopic brain tissue in the orbit. Arch Ophthalmol 1987; 105: 390-2.

7 Holbach LM, Naumann GO, Font RL. Neuroglial choristoma presenting as congenital lid tumor. Graefes Arch Clin Exp
Ophthalmol 1989; 227: 584-8.

8 Hutchison DS, Green WR, Iliff CE. Ectopic brain tissue in a limbal dermoid associated with a scleral staphyloma. Am 7 Ophthalmol 1973; 76: 984-98.

9 Emamy H, Ahmadian H. Limbal dermoid with ectopic brain tissue. Report of a case and review of the literature. tissue. Report of a case and re
Arch Ophthalmol 1977; 95: 2201-2.

10 Hrapchak RJ. Immunohistochemistry. In: Sheenan DC, Hrapchak BB, eds. Theory and practice of histotechnology. Columbus: Battelle Press, 1987: 310-26.

11 Kindblom LG, Angervall L, Haglid K. An immunohistochemical analysis of $\mathrm{S}-100$ protein and glial fibrillary acidic protein in nasal glioma. Acta Pathol Microbiol Immunol Scand [A] 1984; 92: 387-9.

12 Bozoky B, Stiller D, Ormos J. Immunohistochemical demonstration of glial fibrillary acidic protein (GFAP) in nasal gliomas. Acta Histochem 1987; 81: 117-23.

13 Barkovich AJ, Vandermarck P, Edwards MS, Cogen PH. Congenital nasal masses: CT and MR imaging features in 16 coses. Am $₹$ Neuroradiol 1991; 12: 105-16.

14 Braun M, Boman F, Hascoet JM, Chastagner P, Brunet A Simon C. Brain tissue heterotopia in the nasopharynx. Contribution of MRI to assessment of extension. $\mathcal{F}$ Neuroradiol 1992; 19: 68-74. 